\title{
APUESTA POR LA DEONTOLOGÍA EN EL TRATAMIENTO DE LAS INFORMACIONES RELATIVAS A SUCESOS.
}

\section{COMMITMENT TO ETHICS IN THE TREATMENT OF THE INFORMATION ON EVENTS.}

\begin{abstract}
AUTOR/ES
Juan Tomás Frutos: Profesor asociado de la Facultad de Comunicación y Documentación. Universidad de Murcia. Murcia (España).

jtomas@um.es
\end{abstract}

\section{RESUMEN}

En este trabajo hacemos una reflexión sobre el tratamiento informativo que se lleva a cabo en la actividad que conocemos genéricamente como Periodismo de Sucesos. Se ofrece una visión crítica de lo que brindan los medios, y se responsabiliza de las distorsiones que se producen a las prisas y a la búsqueda de audiencias y de una cierta rentabilidad económica o de carácter social. La autorregulación es la solución, o parte de ella, así como se aboga por un reciclaje y una formación permanente de los profesionales, al tiempo que defendemos una transformación en los consumos, en sus rutinas, por parte de los telespectadores. Refrescar el Periodismo sosegado y cuidadoso de las "maneras" es otra necesidad, junto con una mayor implicación de las organizaciones ciudadanas.

\section{PALABRAS CLAVE}

Periodismo - Sucesos - Ética - Responsabilidad - Consejos.

\section{ABSTRACT}

In this work we make a reflection on the informative treatment that is carried out in the activity that we know generically as Journalism of Events. A critical vision offers what the Media shows, and takes responsibility of the distortions that take place due to the hurries and to the search of hearings and of certain economic profitability or of social character. The self-regulation is the solution, or part of it, as well as one pleads for a recycling and a permanent training of the professionals, at the time that we defend a transformation in the consumptions, in its routines, on the part of the viewers. To refresh the calm and careful Journalism of their "good ways" is another need, together with a major implication of the civil organizations. 


\section{KEY WORDS}

Journalism - Events - Ethics - Responsibility - Advices.

ÍNDICE
$\boldsymbol{\sim}$ INTRODUCCIÓN
ㄱ. 1 . EL PERIODISMO DEBE DEFENDER LAS LIBERTADES CIUDADANAS
ㄱ. 2. POR LA TEMPLANZA EN LA COMUNICACIÓN PERIODÍSTICA
$\boldsymbol{\sim}$ 3. MEDITACIONES EN POSITIVO SOBRE LOS MENESTERES INFORMATIVOS
^ 4. CONSIDERACIONES SOBRE LOS ESPECTÁCULOS DEL UNIVERSO MEDIÁTICO
그 5. EL PERIODISMO DE SUCESOS ADMITE ALGUNOS CONSEJOS
2 6. UN PERIODISMO BASADO EN LA ÉTICA
$\boldsymbol{\sim}$ 7. BIBLIOGRAFÍA A TENER EN CUENTA
$\boldsymbol{2}$ 8. INFORMES UTILIZADOS
$\boldsymbol{2}$ 9. MÁS FUENTES BIBLIOGRÁFICAS

\section{INTRODUCCIÓN}

La tesis en la que nos movemos en esta secuencia de artículos parte de la necesidad de ahondar en la responsabilidad de servicio público a la ciudadanía en cuanto se refiere al tratamiento de las informaciones sobre sucesos de todo género. Las víctimas han de ser (y no siempre lo son) los ejes principales que motiven en positivo este tipo de noticias. Además, hay que tener en cuenta los derechos de los telespectadores, que han de recibir una información veraz y ver respetadas sus ideas, su sensibilidad y sus pretensiones de conocer con juicio y con equilibrio aquellos eventos que más le atañen. Los derechos de los menores merecen un punto de reflexión aparte. La deontología, la ética, es la base para evitar excesos y para conseguir la pretendida y necesaria auto-regulación del sector y en lo que concierne a su ejercicio. En este ámbito nos movemos en las páginas siguientes.

Con suma humildad, y con el afán de compartir el conocimiento y aprendizaje desde la experiencia diaria, os hago llegar una serie de análisis, de interpretaciones, de consideraciones y de explicaciones acerca de lo que ocurre en el entorno del Periodismo de sucesos. Como podemos constatar cada día, los eventos acaban, a menudo, dominando a la propia noticia, en la cual se cumple de manera extraordinaria la máxima de MacLuhan en el sentido de que el medio es el mensaje, al cual condiciona en múltiples ocasiones en exceso. La necesidad de ponderación y de respeto de los derechos ciudadanos en consonancia con la libertad de información subyace en todas estas reflexiones, que se hacen desde la consideración de que ninguna verdad tiene carácter de absoluta, y menos cuando hablamos de Comunicación en general y de Periodismo en 
particular. Quizá estas impresiones, algunas reiterativas en estos escritos, sirvan de acicate para ulteriores meditaciones donde la ciudadanía tendrá siempre, y es normal, la palabra.

\section{EL PERIODISMO DEBE DEFENDER LAS LIBERTADES CIUDADANAS}

El equilibrio es pura sinceridad, que es un fruto muy interesante y atractivo para convencer y convencernos. El punto medio, como se suele repetir, nos lleva a posturas virtuosas en lo intelectual, en lo espiritual, y hasta en lo material. Debemos aplicarlo en asuntos de tanta sensibilidad como la Comunicación, que gira en el universo de los intangibles, de lo no siempre ponderable. El axioma ha de ser claro: los derechos y libertades públicas e individuales han de ser el referente en las prácticas periodísticas. Hay veces en que las condiciones de los medios informativos, con sus variados tonos e instrumentales, alteran los mensajes. En tales casos hemos frenar algunas tendencias. Nos explicamos. Las prisas por llegar los primeros a la hora de informar nos han dejado, a los periodistas, a las empresas también, con la credibilidad por los suelos, y sin esa valoración es difícil que podamos defender el campo de la información con el ahínco y el tesón que nos gustaría y que seguramente tanto precisamos. Hemos de huir de las premuras, del sensacionalismo, del divertimento a ultranza, de las informaciones sin cautelas, y nos hemos de implicar mucho más por llegar a tiempo, pronto si es posible, pero, ante todo, debemos hacerlo en óptimas condiciones. No vale todo, ni como meditación ni como actividad diaria u ocasional.

A menudo, cometemos ciertos errores, y proferimos unas torturas que ocasionan que las víctimas se precipiten antes de ser juzgadas en el abismo de un juicio que no tiene, ni mucho menos, las garantías mínimas constitucionales. Estamos, los profesionales de la información, para ser testigos, para trasladar lo que dicen instituciones y ciudadanos, pero con el debido contraste, sin acusar antes de que se produzcan resoluciones judiciales. No secuestremos la realidad, ni mucho menos la verdad, o las consecuencias serán muy duras para el sector, ya diezmado en su credibilidad. Insistamos en que esto se produce a veces incluso inconscientemente, por la presión de trabajar con velocidad y sin los necesarios recursos y elementos, incluyendo entre ellos el tiempo suficiente para desempeñar el quehacer debido.

Vivimos del crédito que nos da la ciudadanía, o que debería darnos. Sin él, no somos nada ni nadie como colectivo profesional. El periodista vive de decir la verdad, pero los ciudadanos y ciudadanas no piensan que la digamos, aunque mayoritariamente lo hagamos, y así lo resaltan en las encuestas que hacemos al respecto. Hemos de cambiar de actitudes. La presunción de inocencia, el derecho a la intimidad, la preservación de la imagen de todos, especialmente de los menores, de los más desfavorecidos y de los que precisan de garantías suficientes para tener una cierta presencia social han de sostener la 
estructura de la Comunicación y del Periodismo. El papel del periodista es esencial, y hemos de demostrar que lo es, que lo sigue siendo. Refresquemos conceptos.

Llegar los primeros no tiene sentido, si no decimos las cosas de manera adecuada y proporcionada. Debemos hacer los relatos contrastando las informaciones, destacando lo que sabemos, y lo que no conocemos con certeza ha de ser entrecomillado, puesto en cautela, con los términos de presunción que sean menester. Ya habrá tiempo de contar el resto de la información cuando sepamos las cosas con más precisión. Aparezcamos con los datos exactos, o esperemos a tenerlos. Las exclusivas hacen daño cuando no son tales, cuando son frutos de mentiras, o cuando son medias verdades, que son las peores falsedades.

Además, cuando nos equivoquemos, hemos de saber pedir perdón, de dar las respuestas necesarias, de corregir los datos incorrectos, de dar las versiones convenientes, procurando que la sociedad sepa en todo momento lo que sabemos de verdad. No tengamos prisa, por favor. El exhibicionismo, el amarillismo, la búsqueda de la truculencia, a menudo para dar con más audiencia, hace un daño tremendo a los profesionales y al sector y nos introduce en una dinámica dañina y de tierra quemada.

No olvidemos que el derecho a informar tiene sus límites en el respeto de los derechos de la ciudadanía. No hay excepciones. Por otro lado, hemos de ponderar las libertades y las consideraciones de todos/as: cuando hagamos más daño que beneficio, en el caso de equivocarnos, hemos de mantener la información guardada hasta que sepamos que los datos son ciertos, o hasta que podamos complementar las visiones que tengamos del acontecer que nos ocupe.

Volamos muy alto (hemos de recordarlo), y tenemos una responsabilidad con la sociedad, con todos y cada uno de sus integrantes. No hagamos mal la labor periodística, o la interpretación que se tiene de nosotros perderá muchos enteros, quizá demasiados. Estamos a tiempo de enmendar la plana, y de ir con un poco de más sosiego. No infrinjamos torturas y desasosiegos a posibles verdugos antes de saber si lo son, o, de lo contrario, si lo hacemos mal, se presentarán como víctimas anticipadas de un sistema que no terminamos de aprovechar congruentemente en todas sus fases y elementos. Busquemos calidad, fundamentalmente, en vez de cantidades en todos sus extremos, que nunca son buenos.

Lo importante no es ser los mejores y los más famosos: lo relevante es ser buenos. Lo que pedimos es autocontrol. El fin primero y último ha de ser la ciudadanía, a la cual servimos por mandado constitucional. El respeto estricto y escrupuloso nos hará recuperar el prestigio social que es la base de nuestro quehacer. Merecemos una visión un poco más halagüeña y alta por parte de la sociedad a la que dirigimos nuestro afán. La conciliación ha de ser la actitud. 


\section{POR LA TEMPLANZA EN LA COMUNICACIÓN PERIODÍSTICA}

De vez en cuando hay que buscar historias y relatos con moraleja. Dediquemos tiempo a ver lo que acontece y a valorarlo. No pasemos de puntillas sin dar con las claves de lo que nos debe importar. La naturaleza humana y el ecosistema en el que vivimos tiene un poco de todo. La visión también entraña contemplaciones dispares. Eso, en esencia, es bueno. Hay teóricos que nos hablan de la existencia de colores fríos y cálidos, en función de la percepción o de la impresión que nos provoca su contemplación espontánea o reiterada, esto es, a la primera de cambio o de manera constante. Es así. La subjetividad, nuestra propia formación, la impronta que nos deja la experiencia y el aprendizaje individual y colectivo hacen que veamos lo que nos rodea en base a las circunstancias previas que hemos contemplado o incluso heredado genéticamente. Avisémonos una y otra vez que la mesura contribuye a una buena gestión.

Como esto es así, hemos de procurar en todo momento tener en cuenta no sólo lo que contamos, sino también cómo nos llega, en qué momento, con qué condicionantes, $\mathrm{y}$, en paralelo, fomentando la necesaria empatía con aquellos/as que nos rodean y que, sin duda, nos ofertan su ideario día tras día conforme a lo que han ido recibiendo desde sus respectivas atalayas.

Se suele repetir, porque así lo han dicho muchos a lo largo de los siglos, que el punto medio es virtuoso, y no porque tenga que ser el único, sino porque permite un entendimiento más de conjunto. Fomenta, como advertimos por lógica, equidistancias, o, dicho de otro modo, unas mayores cercanías frente a lo ventajoso y a lo que no lo es tanto. Por ende, debemos intentar que los términos denoten frío y calor, en sus acepciones más amplias, para todos/as, de modo que nadie se sienta ignorado ni agredido en sus pensamientos, al menos no de manera radical. El consenso es la base para que prosiga la comunicación, y por ello ésta debe entrañar esa simiente. Miremos con todos los colores, con sus variopintas gamas, con sus aristas y líneas rectas.

Persigamos y hallemos esos linajes que nos invitan a que el pacto sea la base para resolver los conflictos, e incluso para prevenirlos. Es lo mejor, debe serlo. No dejemos para mañana esta actitud, pues el coste puede ser mayor. No olvidemos que la relatividad de las cosas hace que no siempre veamos los eventos como nos gustaría. Por consiguiente, tener en cuenta que cada cual es diferente, a menudo maravillosamente distinto, y que entre todos podemos construir una realidad, es una actitud que engrandece al colectivo en su conjunto, sea cual sea su parecer, siempre que éste tenga en cuenta los derechos y libertades de cada uno.

Llega periódicamente el invierno, y el frío sucede al calor. Es el ciclo de la vida, y como tal hay que verlo. Lo aconsejable es aceptar las vivencias cuando llegan de manera natural y en los tiempos y formas que toca, según las estaciones humanas, terrenales y hasta medioambientales. Es bueno el cambio, incluso para no mal acostumbrarnos a lo que nos acontece. La existencia humana es eso: un poco de todo, con miradas y 
temperaturas diversas. Ahí están la lindeza, el amor, el secreto de un poco de felicidad, el ansia y la pasión como estructuras fundamentales de nuestro caminar... Busquemos, pues, el calor, pero dejemos que el frío de vez en cuando nos despierte a otros sentimientos comunicativos. Son. La templanza, la moderación y la perspectiva de todos/as y para todos/as son buenas compañías. En la contemplación hay mucho aprendizaje, como en el silencio, como en el análisis. Tomemos nota. El deseo de compartir tiene que ir tan lejos como sea menester para que los demás sepan que nuestras intenciones les tienen en cuenta, que saben de ellos, que existen con sus anhelos, con lo que son, con lo que somos. Apostemos en todo instante por el equilibrio.

\section{MEDITACIONES EN POSITIVO SOBRE LOS MENESTERES INFORMATIVOS}

Conforme avanzamos en el trecho profesional $\mathrm{y}$, aunque no soy dado a regalar consejos, quizá porque no me creo en posesión de ninguna verdad (con el paso de los años lo tengo más claro), sí me gustaría acercar un poco de luz sencilla en torno a lo que considero básico en la formación personal y profesional de los informadores, incluyendo, claro, a quién les escribe esto.

Lo primero que me gusta destacar es básico. Recordando a Ryszard Kapuscinski, subrayemos que debemos ser y comportarnos lo mejor que podamos, teniendo a los universales éticos como referencias. Defiendo, sobre todo, el mantener actitudes solidarias, el compartir todo, el desarrollo de la empatía, el fomento de la ayuda a los demás, el ser positivos, el adecuarnos a lo que sea más equilibrado y ponderado. Darnos tiempo es casi siempre un soplo de coherencia a la hora de tomar alguna decisión o de realizar alguna actividad. Cuando se pueden pensar las cosas se hacen mejor, o, sencillamente, no se llevan a cabo.

Actuemos, pues, baremando todo lo que podamos, con justo sosiego. Consultemos varias fuentes, digamos, con la mejor de las intenciones, lo que sucede, y pongamos en marcha un buen sentido de la orientación desde el que nos dispongamos a abrir la mente y a considerar al resto de conciudadanos y conciudadanas como iguales, porque lo son: no lo olvidemos.

Pensemos que cada cual tiene su verdad, que podemos aprender incluso del que, a priori, menos conoce. La vida es un viaje hacia la experiencia en la mejor de las perspectivas. Lo ideal es que tratemos de ir enmendando los equívocos o los frenazos que se vayan produciendo. No debemos desanimarnos por ellos: es normal que acontezcan.

Procuremos, cada jornada, aprovechar todos los recursos disponibles, desde el mismo amanecer, para realizar el bien, para mejorar nuestra cultura y nuestro intelecto y 
para subirnos al carro del progreso bien entendido, en compañía de los demás (insisto en ello), fundamentalmente de quienes menos tienen. Hay que restañar heridas y devolver esos aportes mínimos que todo ser humano precisa.

Los corazones han de ir abiertos de par en par, inclinados hacia el infinito, prestos a contemplar la luz de los convecinos/as. No hay nada más sencillamente útil para nuestro bienestar, para el cultivo de lo que nos rodea, que generar paz, sosiego, tranquilidad y una base coherente y fuerte para edificar, desde el cariño, el aprecio y hasta el amor, un engranaje fuerte y fortalecido.

El corazón a la escucha, el no dejarnos condicionar por aspectos estériles y baldíos, el seguir adelante ante la adversidad y frente al fracaso, son armas que, junto al coraje, nos invitan y permiten llegar un poco más allá. Sabemos que hace más el que quiere que el que puede: siempre es de esta guisa. Dejemos paso a la voluntad. Practiquemos cada día con el fin de incrementar en lo cuantitativo pero, sobre todo, en lo cualitativo. Podemos alcanzar altas cotas de dichas con este ademán.

\section{CONSIDERACIONES SOBRE LOS ESPECTÁCULOS DEL UNIVERSO MEDIÁTICO}

El periodismo se ha convertido en los últimos años en algo que se distancia de lo que conocimos hace un par de décadas tan solo. El frenesí es muy grande, al menos en aquellos medios y productos de alto consumo societario. Los principios de respeto a una audiencia amplia y plural se han quedado en un segundo plano en aras de conseguir altos índices de seguidores, que parecen primar sobre otro tipo de elementos y/o factores. Ello nos coloca en un lugar complicado en el que el silencio nos hace cómplices de una realidad que se basa en demasiados excesos. Deberíamos mirarlos y hablar de ellos, para sanar un poco, para mejorar, para cerciorarnos del camino justo y correcto. Recordemos, una vez más, que en el punto intermedio está la virtud.

Detenernos de vez en cuando en la realidad que nos circunda es bueno, porque, en todo caso, nos ofrece unas interpretaciones tan sugerentes como necesarias. Meditemos sobre lo que ocurre y acerca de la intencionalidad o casuística de los eventos cotidianos. La observación de la realidad de los medios informativos nos llena de escándalo. Sí, probablemente no hay una mayoría que practique un mal periodismo, pero, indudablemente, los productos comunicativos que más suenan e inciden en la sociedad, con sus honrosas excepciones, tienen estandartes difícilmente defendibles. Cada vez observamos más ejemplos de un tipo de periodismo que hace daño a la vista, a los espíritus y a lo más básico respecto a lo que debería ser la decencia formativa del telespectador. El periodismo, por así decirlo, tipo espectáculo que nos rodea, sobre todo en la última década, nos ofrece una visión de una sociedad altamente tolerante con unos niveles de agresividad y de insolidaridad sumamente "traumatizantes", dañinos incluso, 
perniciosos. Los medios de comunicación, tildados en algunas ocasiones de informativos, no siempre hacen prevalecer este elemento noticioso o novedoso. No debemos aceptar sin un ánimo de crítica ciertos espacios o letras cargadas de puro morbo. El sensacionalismo no ha de primar sobre los intereses de conocimiento que tienen y que deben trasladarse a la sociedad. Si no devolvemos genuino periodismo a la sociedad acabaremos siendo deudores de un compromiso, tácito o escrito, de servir a todas las sensibilidades y a todas las opiniones. Pidámonos, por favor, el desarrollo de unas conciencias cargadas de una mayor denuncia ante lo que contemplamos y/o toleramos.

La cobertura que se hace de accidentes aéreos, de la barbarie de algunas o de todas las guerras, de eventos infames o de penurias en algunos de los rincones menos afortunados de nuestras sociedades o del planeta nos hacen pensar en la necesidad de emprender otro camino en el desempeño de las labores de los profesionales de la comunicación y de los medios. Por ello hacemos algunas reflexiones, y, con permiso, algunas sugerencias. No estamos en posesión de ninguna certeza absoluta, pero sí sabemos que es bueno que pongamos en cuestión el sistema de actuación que nos hemos brindado hasta ahora. El afán es dar con algunas ideas que puedan servir para mejorar el funcionamiento de los medios y su práctica profesional diaria, amenazadas en su credibilidad social para una serie de excesos en la oferta de imágenes que podemos catalogar de manera suave como "impactantes". Todo vale, o eso parece en algunos programas, que acaban fagocitando algunas cadenas, o, cuando menos, sus horas estelares. Se intenta ser "atractivos" a toda costa, sacrificando prácticas de respeto y de tolerancia hacia las personas y sus sentimientos. Nada nos escandaliza ya, o lo hace ocasionalmente, en lapsus cada vez más cortos de tiempo. La vida nos está inmunizando gracias a unos medios con los que estamos siendo extraordinariamente permisivos. La apatía de la sociedad no es buena: la abulia no es un buen cimiento para construir una comunidad moderna y amante de la universalidad del acontecer.

Comencemos, tras estos primeros apuntes, por el principio, esto es, por las razones que llevan a la aparición y al desarrollo de las empresas periodísticas. A menudo ayuda saber de dónde venimos. En el origen de los medios están las ansias de que éstos sirvan de soporte económico, a la vez que han de prestar un servicio público de gestar, producir y difundir informaciones y opiniones sensatas. Los mass-communication-media pretenden, al menos desde la teoría, llevar a cabo tres objetivos que podemos considerar primordiales, que no son otros que informar, formar o educar y entretener, sin olvidar lo que se denomina supervisión del ambiente, lo cual hace que capitalicen una interesante y relevante pretensión a modo de recursos "homogeneizantes" o socializadores (ello tiene ventajas y desventajas). Si la praxis es buena, nos hallamos ante lo deseable, pues, cuando cumplimos bien los fines para los que se han creado estas empresas, correspondemos a la sociedad ese derecho a la información que surge, emana y debe volver al mismo núcleo social. Hay una compensación de deberes y de funciones. Apostamos por ello. 
En cambio, y por el contrario, en sus obras, en su vertiente práctica, es decir, en sus aspectos económicos y empresariales (los de estas corporaciones), prevalecen una suerte de egoísmo o soberbia que distancian a estos servicios públicos de sus verdaderos fines, o de lo que deberían ser, claro. El debate está ahí, y sigue abierto, y es lógico que así sea por la prestancia e interés social que hay detrás de todo ello.

En esta textura y tesitura, la realidad diaria, marcada a menudo por el dolor y el sufrimiento, aparece deshojada y sin su fundamento y espíritu más humano. Reconocemos, porque es así, que hay medios que se comportan adecuadamente. Son la mayoría, pero no son los que más consumo tienen. Prima, en los horarios fundamentales, el espectáculo, $\mathrm{y}$, además, prima a toda costa, como si no hubiera más mirada que atraer audiencia y ganar dinero. La influencia social (el de deseo de influir) queda marcada por encima de otras finalidades. La perversión, por desgracia, está servida, y hay demasiada pasividad en torno a esta situación, ya formalizada en estructura.

Hemos de corregir algunas posturas o algunos afanes que lo que persiguen no tiene nada que ver con lo que cuentan los manuales o lo que contamos cuando tratamos de hablar de una profesión que cada vez guarda menos romanticismo. No lo vemos en aquellas actividades que supuestamente triunfan. Las lesiones que se están produciendo no parece que vayan a sanar por sí solas. Todos debemos arrimar el hombro para implementar y mejorar el quehacer cotidiano, que rompe la frágil frontera entre lo deseable éticamente y lo que se hace finalmente.

La ética, la deontología, la moralidad en el mejor sentido, es la gran asignatura pendiente en un proceso societario que hace que predominen determinados vectores de influencia relativa. Así estamos. Nos agotamos en esfuerzos de recorrido muy corto, que apenas vislumbran lo que ha de ser, o debería ser, un comportamiento variopinto y acogedor para las circunstancias de toda índole. Sublevarnos ante ello podría ser, aunque sea de manera ocasional, una opción. Además, es conveniente que incidamos en que los códigos deontológicos han de ser algo más que papel escrito. Hemos de asumir un compromiso mayor, primero con los propios medios, y, en segundo y primordial lugar, con la misma profesión y la sociedad. La deuda, y, asimismo, la obligación son mancomunadas. Subrayemos, sin miedo a ser reiterativos, que los valores son la base de cualquier mundo democráticamente avanzado. Si sólo cultivamos la materia no llegaremos a ninguna parte. El mayor tesoro reside en nuestro espíritu, y no hablamos enteramente de religión. De nada sirve, como se dice en alguna parte, que se pierda el alma alada por el camino, si lo que conseguimos, siempre fungible, se queda en alguna parte que no experimentamos. Hemos de buscar climas adecuados, positivos, con impresiones educadamente compartidas. Juntos en la experiencia vital podemos alcanzar un poco de más éxito, anónimo, diluido entre toda la comunidad misma con la que contribuimos. Los medios han de favorecer esta perspectiva. La experiencia hasta ahora debería servirnos de acicate para amortiguar los problemas y corregir los equívocos, que siempre se producen, y que, de algún modo, son inevitables. De ellos hemos de aprender. 


\section{Pacto social}

El deber por encima de todo. La obligación tácita, o incluso escrita, que han adquirido los medios respecto de la sociedad o comunidad donde se hallan incardinados adquiere tintes de presión en más ocasiones de las que debemos recordar. La competencia por llegar antes, mejor y a más gente es descomunal. No hay descanso. Se busca el atractivo a ultranza, de cualquier manera, y, claro, con esas velocidades de producción y de difusión se producen errores. Hay que dar información en todo momento y lugar, a toda costa, con una instantaneidad que hasta hace daño. Ése es el gran peligro. La búsqueda de dividendos económicos es aplastante. Por eso, porque hay que rentabilizar los recursos, las plataformas, trabajamos con clichés, y todo acaba siendo relativo y relativizado. El interés humano suple al interés general y público, que, por desgracia, no siempre coinciden con los parámetros que manejan los "media". No olvidemos que para entender estos conceptos hay que aprenderlos lentamente, paulatinamente, con ejemplos diarios. No van por ahí los modelos sociales.

Todo vale. Hay que llegar antes y con más provocación. La sensiblería barata, el amarillismo, el morbo, el atractivo a ultranza... todo ello, por desgracia, forma parte de ese espectáculo que se ceba en la pena, en el dolor, en las lágrimas, en los gritos, en el espanto y en la violencia. Lo peor es que vestimos esto con la idea de que hablamos de una visión social. Le damos una mano de pintura de ayuda a los demás, de contribuir a contar lo malo que ocurre. No es cierto. La fórmula perniciosa nos lleva desde las máximas audiencias con sensacionalismo hasta la consecución de más publicidad, y, por lo tanto, de más dinero para las productoras y/o distribuidoras de los espacios o programas de éxito. El círculo es vicioso. Hemos generado una espiral donde lo informativo deja de serlo a las horas de un acontecimiento, y ya entramos en otra dinámica.

No seamos pueriles. La finalidad básica no es informar, ni mucho menos informar bien. La idea es llegar a cuanta más gente mejor con el objeto añadido de vender sus productos a un gran número de personas. El producto o servicio puede ser influencia social en sí, esto es, estar en los hogares para brindar eso que se llama "opinión pública". Lo malo de todo esto, lo peor, es que con estos sistemas comunicativos imperantes no generamos la conciencia crítica que precisa toda sociedad. Los beneficios económicos están detrás y delante de cualquier gestión mediática, o, al menos, de la mayoría de ellas. Si miráramos a los dueños de los capitales y de las empresas mediáticas nos daríamos cuenta de que se dedican de manera principal a otros negocios y que el de la comunicación es uno más de su poderoso engranaje productivo. No es para sentirnos orgullosos de ello. Los valores, los ideales, permanecen oscurecidos por otras máximas financieras. Es una pena. Hemos tenido, indudablemente, oportunidades para cambiar todo esto, pero suponemos que nos han faltado agallas para ello. Los administradores públicos tampoco han contribuido a una mejoría. 
En todo caso, pongamos las cosas en su sitio. La sociedad debe hacer y vivir una gran revolución en muchos órdenes. La apatía no vale, no funciona, no es buena. La solidaridad y la entrega hacia las mejores causas consensuadas se han de ver a través de los medios de comunicación de masas, que han de ser también un buen parangón en lo que concierne al servicio público y a la voluntad de consenso. Resaltemos el papel de enseñanza y de formación en el que han de estar, entre los primeros, los medios de comunicación masiva. El respeto y la educación en sentido extenso han de ser las prioridades. No lo olvidemos, pues el beneficio es, o debe serlo, para todos. Asimismo, subrayemos que esta influencia en positivo no se improvisa de la noche a la mañana. Debemos postularla cada día, de manera que las rutinas de consumo sean un poco más coherentes, equilibradas y acertadas. El juicio se adquiere sin prisa.

La era es digital, audiovisual. Estamos en un mundo visual y visualizado. Por supuesto, manda la imagen. Las estampas, fijas o en movimiento, lo inundan todo. Esto es algo que debería llenarnos de orgullo, pero no es así, porque nos hallamos ante una optimización de lo gráfico en el mundo audiovisual, en la esfera televisiva, siempre a costa de una seducción desde lo fatal, desde la ruptura, desde la fragmentación de lo que deberían ser elementos "vertebradores" y cohesionadores al mismo tiempo. La existencia precisa de valores, de conveniencias que capten los resortes básicos del universo en su conjunto, hilvanado para que nadie sobre y para que todos nos sintamos parte del bosque comunicativo.

Reiteremos que no hallamos una actuación proporcionada en los espacios de éxito en lo que contamos ni en cómo lo contamos con una óptima combinación, la cual sería deseable. Prevalece lo que se ve. Prima el dinero y la influencia. El ruido, que es un filtro y un obstáculo comunicativo, está presente en muchas de las comunicaciones, y, cuando no lo está, dudamos de si está escondido en alguna parte y en si no lo hemos visto. Todo se coloca el hábito de la vacilación, y eso, en sí, es un nuevo filtro. Los números son los que cantan victoria. Queda atrás la figura de lo humano. Los comienzos de esta era del video y del cine se muestran ingenuos dada la evolución actual. El escándalo está a la orden del día. Cuando no se halla fácilmente, se busca, y algo se encuentra, y se estira... No importa la fama de nadie, ni su prestigio, ni la distorsión de la estampa que transmitimos de las personas. Los derechos elementales quedan en una segunda estancia, siendo la primera la búsqueda de ganancias. Además, todo parece llevarnos como un río caudaloso tras una perenne tormenta. Los unos y los otros hacen lo mismo, para que nadie gane a nadie. Hay una especie de actividad compartida para que ninguna empresa lidere el espacio virtual por un mayor aprovechamiento de esto que decimos. No sabemos sacar lustre a los ingentes recursos de los que disponemos. Es una pena, pues somos unos privilegiados y no lo vemos. Convendría reprogramar nuestra forma de comportarnos. Estas vehemencias no nos conducen por sendas acertadas. 


\section{Maridaje de soportes}

Todo ha cambiado. La mudanza ha sido atroz. La vida está puesta patas arriba. Hay demasiada confusión. Hemos complicado hasta lo más sencillo. Nos enredamos con caracterizaciones que, a menudo, ni damos. Nos faltan definiciones de conceptos, y en eso debemos ser valientes desde la sencillez. Siempre insistimos en que la mezcla de los formatos y de los soportes constituye el gran problema actual de los medios. Hay profusión de todo, y no sabemos cuáles son los espacios en estado puro, o pseudomodélico. Unas veces no los cultivamos por hastío o pasotismo, y, en otras oportunidades, porque desconocemos su formato original. Hemos visto y escuchado mucho, pero quizá no lo suficientemente, o puede que no con el consiguiente ánimo de atender y de aprender. Quizá se deba a la premura en la que estamos incidiendo en este artículo.

En todo caso, en el consumo hay dos partes principales. Pensemos en los emisores, y también en los receptores. Asimismo, la difusión de "formatos polucionados" es un problema y una deficiencia de sus audiencias, de las de los medios, claro. Son, en definitiva, quienes consumen, y lo hacen, aunque se quejen en los pasillos o en los comentarios de cantina o de trabajo. Hay un dejar hacer en los telespectadores, e igualmente una falta de interés en aprender y formarnos. Resaltemos que no siempre se entiende lo que ve. No es fácil interpretar lo que se vende de una manera y se brinda de otra bien distinta. No llegamos a marcar las directrices y los límites de lo que ocurre y de cómo se ofrece. Hay saturación informativa, hay un exceso de lo atractivo en detrimento de la información pura y genuina.

En parte, el no entender, el no saber lo que ocurre y cómo se nos vende, el que carezcamos de la suficiente perspectiva es un problema de años, de no dedicar el tiempo suficiente a conocer lo que sucede. A diario se cuentan multitud de cosas. En realidad, no parece importarle a nadie la desinformación que viene detrás. Las hecatombes, los espectáculos catastróficos se superponen al análisis de la verdad o de lo que podría ser una aproximación a ella. Lo mixto triunfa, pues se trata de conseguir cuanta más gente mejor. Es un poco locura. Convendría poner un poco de medida a lo que realizamos o a lo que consentimos. La medida tendría que ser el propio ser humano, lo que se ofrece y lo que se le quita. No puede haber una inclinación constante hacia un único lado de la balanza.

Da miedo, y también tristeza. Es una pena. La calidad queda en un segundo lugar. Importa la cantidad, y, además, es relevante en muchos aspectos que no deberían contar, o no deberían contar tanto. Mandan los números. Nos desayunamos con las cifras y las estadísticas, que son pequeñas verdades, o grandes mentiras, según se mire. Como hay que llegar a todo el mundo se apela a los sentimientos, a los corazones, a esas escenas o eventos que todo el universo de consumidores entiende, o atiende... Provocamos las mentes en vez de edificarlas. Tensamos la cuerda en vez de calibrar la que necesitamos para hacer estupendamente las cosas. No hay nutrientes en lo que ofertamos en los 
medios, no los necesarios, y a menudo estas empresas, sus programadores, sus directivos, no tienen en cuenta lo que conviene a sus audiencias, sino aquello que las capta lo más raudamente. Unas veces contemplamos la realidad que describimos con una cierta frialdad, y en otras ocasiones nos declaramos con tan poco tiempo que ni lo pensamos. Se olvidan derechos, se dejan atrás los deseos de los grupos no tan numerosos (pues son menos rentables), y entramos en una espiral de difícil salida. Hay que cambiar la idea de que hay que hacer de todo para todos. No siempre lo universal, en este mundo de modas y de consumismos variados, es lo mejor para todos. Los modelos financieros, que se están demostrando fracasados en lo económico, también han devaluado la visión moral de la sociedad. No han servido, como nos decían, para mejorar, para alcanzar el bienestar. Lo peor es que apenas nos queda colchón. Como no transformemos esta coyuntura, no será fácil respirar en aras de las defendidas libertades de información y de opinión.

Con este panorama cambiamos, a peor, las tendencias y los hábitos. La comunicación es rutina, y ésta se encamina hacia fuentes de dudosa factura. Los usos y costumbres son convenientes para actuar en determinados momentos, para alcanzar cotas de productividad, pero nos meten en unas formas de actuar que nos distancian de la esencia de las actividades que desempeñamos. No hay respeto, no hay tolerancia, no hay educación. Lo pésimo de ello es que lo vendemos, y no sólo lo toleramos. Todo ha de basarse en el morbo, en el sensacionalismo, en crear imágenes de dolor atractivas, o de violencia, o de verdugos y víctimas. Los conflictos son los que atraen al telespectador, que se siente acobardado, llevado de la mano de una inercia nada constructiva. Además, estos consumos se dan porque nos hemos habituado a ellos. Salir de esa estructura de funcionamiento no es sencillo. Mostramos a la sazón sufrimiento pero no indagamos en lo que hay tras él. No parece importarnos las personas, sino el valor económico que procuran sus historias a nuestras programaciones. Es detestable y rechazable. Sin duda, si cayéramos en la cuenta de lo que hacemos, de lo que ocasionamos, algunos cambios se producirían. Cuando hacemos algún tipo de encuesta a los profesionales, como al mismo público en general, la coincidencia mayoritaria es que no sólo no somos creíbles, no lo suficientemente, sino que, además, nos falta un poco de medida en lo que llevamos a cabo diariamente en el desempeño de las labores periodísticas.

\section{Noticias y rumores}

Aunque parezca obvio, no se interpreta siempre la actividad periodística con una actitud lógica. Si analizáramos las noticias que se dan por televisión (también en otros soportes), un porcentaje altísimo no serían seguramente catalogadas de auténticas noticias. Hemos de diferenciar, entre otras cosas, entre noticias y rumores. Si hiciéramos ese citado análisis, la novedad, lo nuevo, no aparecería por ningún lado. A veces incluso no tiene nada que ver lo que contamos con la imagen con lo que relatamos en los textos "locutados". Por desgracia repetimos hasta la saciedad hechos supuestamente noticiosos que no lo son, o que no son tanto. Todas las grandes cadenas caen en esa tentación. Son versiones mediáticas o mediatizas convertidas en un auténtico circo romano, en puro 
espectáculo vacuo, estéril que solo busca llamar la atención y el interés de una audiencia tan incauta como numerosa. Les hemos acostumbrado a ello. Muchas de las grabaciones televisivas que mostramos, así como de esos innumerables directos que contribuyen al espectáculo, serían sueltos cortos de un periódico hace unos años. Las ponderaciones han variado. Su valor informativo no solo es cuestionable sino que buscan de una manera superficial unos conceptos de víctimas y verdugos que solo generan estereotipos y tópicos que apenas contribuyen a buenas escenas comunicativas. Los clichés son cómodos para trabajar, pero, igualmente, incomunican. Conviene recordar la danza de muertos que implican y suponen muchos de los accidentes que reiteramos en las pequeñas o grandes pantallas como si se tratase de una historia cinematográfica que no afecta a personas reales. El dolor es tan tremendo que no mostrarlo bien es denunciable desde todo punto de vista. Asimismo, conviene que recordemos lo que todos sabemos: con la incidencia reiterativa distanciamos a los telespectadores de las esencias que queremos trasladarles.

Ante todo esto defendemos la autorregulación del sector. No puede ser de otro modo. Poner límites defendiendo una regulación consensuada y pactada de los profesionales y del sector es lo más aconsejable. Es necesario que sepamos hasta dónde podemos llegar, cómo podemos hacerlo, y de qué manera. No podemos jugar con las personas como si fueran meros números, que no lo son. La esfera entre lo público y lo privado, entre lo importante para la colectividad y lo íntimo ha de tratarse con esmero, con mimo, pero también con tesón y con convicción. El beneficio de este acuerdo sería para todos. La credibilidad recuperada ayudaría a que esa parte de la sociedad que no nos consume lo hiciera con más responsabilidad, y que la parte que hemos acostumbrado mal comenzará a entender de otro modo el valor y los fines de un medio tan importante como la televisión.

Estudiemos lo que pasa, hagamos talleres, saquemos conclusiones. La ocupación y la preocupación por esas esferas que se entrecruzan es objeto de numerosos debates y, de vez en cuando, con motivo de algunos eventos o sucesos, de múltiples y repetidas polémicas y controversias que no se terminan de cerrar. La discusión es buena, pero la vehemencia, incluso por las buenas causas, no. El rechazar ese recurso fácil al dolor, al sufrimiento, a la pena, al sollozo de los demás es algo más que una anécdota o una formalidad que hemos de subrayar recurrentemente para quedar bien. La repulsa ha de ser sentida. No aceptemos que las cosas son como son porque las mayorías silentes o no las consientan. El poder del cliente, del consumidor, va por otro lado, o debería. Hemos de ayudarle, en ese sentido, a que sepa elegir y a que tenga capacidad sobre lo que le conviene o no, y luego que elija lo que quiera. Es claro que el menú también ha de ser más variado. No se trata de constatar lo que sucede dentro y fuera de los medios. Hay que reaccionar, hay que hacer algo. Debemos llegar al convencimiento de que actuar así (es decir, que los medios sólo piensen en vender y que a los telespectadores les dé igual) deshumaniza a los profesionales y a sus medios, y, asimismo, a la sociedad toda. Es hora de cambiar el chip. 


\section{Códigos deontológicos}

Meditemos sobre lo que reseñamos, y aportemos y asumamos unas reglas de comportamiento, de compromiso con la sociedad y con nosotros como profesionales y como personas. Los informadores, los comunicadores, las empresas periodísticas en general, y todas ellas de manera conjunta, han suscrito muchos compromisos de respetar la intimidad, a las minorías, de diferenciar formatos, de no recurrir en grado extremo al espectáculo, de tener en cuenta unos coherentes principios editoriales, de acatar unos códigos deontológicos, etc. El problema es que eso no se lleva a la práctica. Decimos mucho y hacemos poco. Nos quedamos en la letra, en las palabras, en las creencias a la hora de dar una charla determinada, pero con eso no vamos, como se puede demostrar, a ninguna parte. Conviene un compromiso formal, y un cumplimiento del mismo. No debemos quedarnos tan solo en la teoría. Dice el refranero que "obras son amores, que no buenas razones".

Hay que trabajar unidos. Si nos juntamos en esto, haremos buenos quehaceres colectivos. La capacidad de maniobra entre todos es mucho mayor. Todos podemos aportar algo. Debemos. La propuesta es que todos nos pongamos de acuerdo en las fórmulas a realizar, en las hojas de ruta que nos han de guiar. El diálogo y la comunicación son cimientos extraordinarios. Es básico que cambiemos las recetas desde el respeto a las personas, a las leyes y al buen juicio. Todo lo que sea dar vueltas a lo mal que lo hacemos sin un propósito real de enmienda es caer en una frustración sin más. La frustración genera distancia y negatividad. Tengámoslo presente. Respetar los hechos, a las personas desde la mesura, desde la virtud que es el punto intermedio, ha de ser el emblema que ha de campear en el ejercicio de una profesión que tiene más de servicio social que de aprovecharse de esa sociedad a la que sirve, o debería, para bailar, en cambio, sobre el dolor de los menos afortunados y atraer más telespectadores y dinero. Esto, a la larga, nos provocará un enorme perjuicio, y conviene que lo tengamos en cuenta más pronto que tarde, antes de que nos detengamos irremediablemente ante lo que precisa pronta solución.

Supongo que se ha hablado en demasía sobre lo que aquí describimos. No es que lleguemos tarde: es que llegamos donde han arribado muchos, multitud. La vida admite muchas demoras. Es verdad. Todo se puede hacer un poco más tarde, pero hemos dejado pasar tanto tiempo que quizá estamos ya cerca de un punto de no retorno, en el que no conviene que caigamos de manera estrepitosa. El cansancio juega en campo contrario. Hemos acudido a socorrer muchas situaciones abiertas. Ahora toca tomar medidas sin dilación. La prisa no es buena consejera, por lo que, prudentemente, tampoco la defendemos. Tampoco lo es la demora consentida desde la ignorancia y el desdén. Podemos adecuarnos a una nueva realidad viva, que nos toca saborear sin darle más vueltas de las debidas. Ajustemos pronósticos y actuaciones. Si miramos con la amplitud del linaje del servicio mayoritario ( $\mathrm{y}$, si es posible, a todos), saldremos adelante con una visión de los medios diferente. Su labor de servicio al interés general ha de escapar, si quiera por salubridad mental, de los intereses meramente financieros. El colectivo ha de 
ser el referente. En ese compromiso, digámoslo sin paliativos, tenemos que estar todos. Nadie sobra. Al contrario, cualquier mano es necesaria. La lista ha de ser jugosamente larga. Pongámonos ya en marcha. El tiempo, más que nunca, es oro.

\section{EL PERIODISMO DE SUCESOS ADMITE ALGUNOS CONSEJOS}

La praxis diaria que, al menos de vez en cuando, o, con una cierta proliferación, detectamos en los medios de comunicación nos lleva a concluir que este Periodismo admite, o debe, algunos consejos como los que aparecen en este apartado. Seguro que se pueden hacer muchos más. Con toda la humildad del mundo vamos a expresar algunas consideraciones y/o opiniones sobre cómo informar acerca de los sucesos y las víctimas que aparecen en ellos. La idea es dar una serie de pautas que nos inviten a hacer un trabajo donde el respeto, la responsabilidad, la altura de miras, la variedad de pareceres y la búsqueda de soluciones a los problemas planteados sean las máximas con las que nos movamos en el desarrollo de estos trabajos periodísticos en concreto Como no podía ser de otro modo, tras su lectura, todas las aportaciones serán bienvenidas. A continuación hacemos algunas reflexiones usando de presentación de las mismas una serie de palabras o de frases que consideramos tan emblemáticas como elocuentes.

\section{Ver en colores}

Aunque la expresión es un poco atrevida, sí que defendemos que seamos capaces de pensar en ilustrar con colores, y no siempre en el sentido literal, todo aquello sobre lo que informamos, fundamentalmente cuando se trate de noticias de calado personal, como son los acontecimientos que involucran víctimas, que siempre albergan un alto componente humano. En este sentido, hay que buscar un atractivo responsable. Igual que los sentimientos se pueden clasificar y catalogar por colores, persigamos las significaciones semánticas que aportan el colorido en verde, por ejemplo, que nos trae esperanza, y en azul, que nos brinda paz y armonía.

Aboquemos, por lo tanto, por los contenidos en una secuencia de colores nominados o imaginados que hagan que la radiografía o el escenario planteado sea un argumento más del consumo de la información que estamos dando. En definitiva se trata de hacer atractiva la presentación. Utilizamos con la expresión un cierto símil, pero tenemos que trasladarnos mucho más allá.

\section{Sintonizar}

Empatizar supone ponernos en la piel del otro, o de los otros. Cuando hablemos de problemas, de incidentes o de accidentes, seamos consecuentes con los protagonistas, que son, lógicamente, de toda condición y circunstancias, e intentemos acercarnos a ellos y trasladar sus actuaciones e ideas a los receptores, con los que hemos de conectar también. Meditemos sobre aquellos ejemplos que llegan mejor, y digamos, asimismo, las cosas para que los niveles afectivos o de interés se desarrollen oportunamente y con una cierta 
mesura. Sintonizar, ponernos en el lugar de los otros, de los demás, ayuda en todo género de informaciones, $y$, fundamentalmente, si éstas versan sobre cuestiones o asuntos de atractivo societario y muy cercano en lo personal, como ya se ha subrayado.

\section{Con visión de un futuro-presente}

Frecuentemente hablamos del porvenir como si éste no llegara. En cuestiones de sucesos, de legislación, de víctimas, de usos y de costumbres en esta materia, no hay medidas o interpretaciones que debamos defender en exclusiva para el futuro. Éste ha de ser presente, pues hemos de considerar la responsabilidad de su mantenimiento y/o defensa como una dinámica actual que hemos de fomentar para corregir iniciativas manifiestamente negativas, así como definir y proteger una perspectiva coherente y de mejora en la persecución y en la búsqueda de un camino lo más adecuado posible. El futuro es ya (no lo olvidemos), y esa apreciación se ha de notar en nuestras informaciones sobre las víctimas, que han de ser tenidas en cuenta en su presente como valor inmediato, sin desdeñar, como es lógico, los daños colaterales o futuros que una mala praxis informativa puede generar. El constructivismo ha de ser una referencia cercana y amable. Tengamos en cuenta que todo va muy deprisa y que hemos de estar atentos ante los cambios que se producen, sobre los que hemos de informar pero con visión amplia. Además, no dejemos en manos del futuro el rendir cuentas a las víctimas, pues, cuando se compensa a éstas tras el paso de un largo período de tiempo, todos somos conscientes de que han sufrido una doble pena, un doble daño, un doble perjuicio.

\section{Aproximar}

Uno de los conceptos que más y mejor funcionan en comunicación es la cercanía. Opera en todos los casos. Con ella construimos la realidad de manera que interesa mucho más al ciudadano. Éste ha de ver con responsabilidad lo que sucede y, asimismo, ha de saber interpretar ( $\mathrm{y}$ hemos de ayudarle a ello) lo que acontece con muestras de un lenguaje entendible y convergente en deseos y afectos. La ciudadanía debe enganchar con las informaciones sobre sucesos y víctimas de éstos desde el sentimiento de que se trata de hechos o eventos que nos influyen a todos/as, y no sólo a los posibles o supuestos perjudicados. La cercanía es un concepto que atiende a todos los códigos empleados y a su comprensibilidad desde los niveles racional y afectivo. El lenguaje, por ende, ha de ser cuidado y asequible. Aproximemos.

\section{Ser responsables}

Hagamos todas las informaciones con responsabilidad. No procuremos el daño de manera gratuita. Ponderemos los derechos y las afectaciones que desarrollamos. Cualquier noticia ha de tener en cuenta el parámetro de la responsabilidad, pero, en este caso de los diversos tipos de sucesos, incidiremos un poco más. Cuando damos cuenta de un mal comportamiento ciudadano, o de lo que sufren otros, o de la desgracia que padecen algunas personas, también hemos de pensar en difundir aquellas actitudes que 
son más óptimas, y no sólo para compensar, sino también para mostrar que la realidad tiene más caras en su enorme poliedro. La responsabilidad en cuestiones victimales nos ha de llevar a intentar que la ciudadanía tenga un mejor comportamiento en este campo y en su interpretación, así como hemos de contribuir a que los responsables de las Administraciones y de las empresas periodísticas desempeñen quehaceres cada vez mejores.

\section{Reciclaje sempiterno}

En todas las materias y secciones informativas hemos de procurar, como periodistas, un reciclaje y una formación que debemos considerar permanente. Leamos todo lo que podamos, vayamos a las fuentes más autorizadas y procuremos conocer, desde el equilibrio, todo cuanto ocurre y cómo es interpretado por unos y otros. Las ópticas, cuando son complementarias, son más enriquecedoras, pero, para trasladarlas, hay que conocerlas previamente. Toca, pues, estudiar y analizar de manera constante. El leer sobre cuestiones éticas y deontológicas puede servir igualmente mucho para el afán que nos ocupa.

\section{Justa medida}

Decía Aristóteles (el mundo de la filosofía griega en general) que en el punto intermedio está la virtud. Es cierto. La templanza y la mesura son bases de la razón y de la búsqueda de conexiones y de comunicaciones reales incluso en lo afectivo. No cometamos excesos, pues luego reparar los daños es muy complicado y requiere, para ello, mucho tiempo y esfuerzo, y, además, no siempre se consigue. Los accidentes, el infortunio, las catástrofes, las hecatombes, las guerras, las agresiones, los incidentes de toda índole... todo precisa una interpretación consensuada. Persigamos, cuando menos, la virtud, aunque sea un poco imposible llegar a ella al 100\%. Que nadie diga que no lo intentamos cada día. Apostemos por la justa medida.

\section{Miremos alrededor}

No se entiende la comunicación si no explicamos las circunstancias en las que nos movemos, es decir, su contexto y su situación. Las condiciones y los condicionantes expresan las formas y fórmulas que hacen que se produzcan los procesos comunicativos. Articulemos las mejores maneras para que los mensajes se atiendan y entiendan. Esto quiere decir que, en el caso de las noticias, reportajes y entrevistas sobre acontecimientos que involucren víctimas, deberíamos explicar el contexto que les envuelve, con sus pros y sus contras, dando cuenta de la evolución y de todo dato que nos permita una comprensibilidad mayor. No demos nada por sabido e intentemos arropar cuanto sucede dando todos los antecedentes que, en cada caso, sean menester. Lo que rodea, en sí, un suceso es, obviamente, parte del mismo acontecer, y, a menudo, el propio evento. Miremos a todos lados. 


\section{El valor de la lengua}

Utilicemos bien las palabras. Éstas tienen un significado, o varios, y precisamente por ello hemos de ser precisos y claros en su instrumentalización. Demos las explicaciones que sean necesarias cuando las cosas no queden diáfanas, o cuando no aparezcan lo suficientemente entendibles. Expliquemos, pues, los términos más oscuros o ambivalentes y tratemos de aludir a leyes, consideraciones y escenarios que contribuyan a un conocimiento elocuente y explícito de lo queremos denotar. Recordemos que el uso del idioma es cuestión de práctica, de mucha praxis.

\section{El tren de la crisis}

Las crisis, cuando se producen, no son sólo de tipo económico. También lo son en lo moral, en lo intelectual, a nivel de apreciación de lo que sucede. Hemos de procurar que los eventos, las iniciativas, las diversas actividades, etc., sean explicadas de manera que, con incluso un cierto deseo de que las cosas mejoren, contribuyamos a una mudanza sustancial, a una transformación seria y responsable. Lo que queremos decir es que las crisis no pueden ser una justificación para actuar de manera amoral y sin tener en cuenta lo que acontece en el entorno, a menudo endurecido por la vida misma que consentimos. Podemos ayudar a superar las crisis con unos análisis coherentes y equilibrados, sin renunciar, claro está, a la crítica, siempre necesaria para el avance societario. Los asuntos que atañen a los sucesos, por su repercusión, por sus connotaciones espirituales y sentimentales (en todo caso, afectivas), son cruciales para la ciudadanía, y por ello hacemos un especial hincapié en la apreciación contenida en este apartado. Resaltemos que el tren de la crisis es, en todo momento, una gran oportunidad para todos.

\section{Otear lo bueno}

Hay que cambiar el chip, la tendencia, las malas rutinas. En vez de mirar lo malo, hemos de contemplar lo bueno. El ser positivos ayuda a que las cosas salgan adelante. El optimismo, la alegría, el contento, sobre todo cuando los trasladamos en nuestra forma de ser y en nuestros lenguajes, contribuyen a que todo vaya de una mejor guisa. Las cosas salen bien, o un poco mejor, cuando la actitud es de creer en que ello es posible. Intentemos que en estas informaciones sobre calamidades y sucesos se vislumbre ese positivismo que tanto mejora los resultados de cuanto queremos narrar y ofrecer a la sociedad. Como diría Popper, lo positivo es un cimiento para todo lo que desarrollamos. Oteemos lo bueno.

\section{Buen comportamiento}

Es una continuación de lo visto anteriormente. El consenso, el pacto, es la base de un sistema verdaderamente democrático. No se trata de estar imponiendo desde el lenguaje o desde los hechos lo que piensa sólo una parte, fundamentalmente cuando hablamos de cuestiones sensibles como es la búsqueda del respeto y de un buen trato a 
quienes son protagonistas de las informaciones de sucesos. Todos tenemos que ver en ello, como víctimas, como espectadores del discurrir diario, como parte de la propia Humanidad, y todos debemos resolver lo más conveniente. Hemos de procurar amoldar los anhelos del conjunto, desde la base de que los acuerdos producen más continuidad en la aplicación de las posibles soluciones. La concordia ayuda en la mejora diaria de nuestras actuaciones, en este caso periodísticas. Tratemos de hallar esa intermediación.

\section{Perspectiva amplia}

El campo comunicativo está lleno de posibilidades. Hay muchas teorías, muchas opciones, muchas miradas. Hagamos caso al corazón, y también al intelecto, y no únicamente al nuestro considerado de manera individual, sino a lo que manifiestan los demás. La amplitud y altura de miras han de ser referentes en nuestro trabajo periodístico, máxime cuando hablamos de informaciones victimales, de una extraordinaria sensibilidad. El corazón ha de estar, como diría el Rey Salomón, permanentemente a la escucha. La perspectiva ha de ser amplia.

\section{Hablemos}

Hablemos de las cosas, y hagámoslo bien. El silencio nunca es rentable. Que no nos digan otra cosa. Puede haber situaciones excepcionales, pero incluso éstas pueden ser cuestionadas cuando las abordamos desde la no declaración de lo que ha pasado, de cómo lo vemos, de cómo ha podido acontecer. Atribuyamos, por supuesto, bien las fuentes. Es una tarea que dignifica a todos. En la medida de lo posible hay que explicar lo que pasa y por qué, y, a menudo, también el para qué. La mesura ayuda a llegar a más gentes. La palabra nos libera en la interpretación más amplia de cuanto significa. Se suele decir en comunicación que el silencio no es rentable. Hablemos, pues.

\section{Pro-actividad}

El proceso comunicativo no es pleno sin que se dé la retroinformación o retroalimentación. Hay que generar una pro-actividad, en este sentido, de los receptores, y, además, hemos de predicar con el ejemplo, con los modelos que vayamos hallando. Los emisores han de actuar con pro-actividad igualmente y han de procurar hacer las indicaciones precisas cuando los receptores así lo reclamen. En el caso de las informaciones de sucesos la complicidad en el conocimiento, en el entendimiento, en el consenso mismo con la ciudadanía, como ya se ha subrayado, es básica.

\section{Presentación diáfana}

Los tradicionales consejos de ser breves, sencillos y de utilizar buenas maneras comunicativas funcionan y contribuyen a que el ciudadano sepa lo que ocurre y, cuando menos, conozca parte de los motivos. Hagamos que esos consejos sencillos permitan que las noticias y reportajes, y/o entrevistas que realizamos, también lo sean, también lo 
parezcan. Si el entendimiento es más alto, también será mayor la empatía. No olvidemos que hemos de ponernos en los lugares de las víctimas para interpretar lo que les ha pasado y para saber cómo contarlo; y, además, nos hemos de ubicar en el lugar del telespectador para que conozca lo narrado y no se sature.

\section{Dinamismo}

Las informaciones sobre sucesos son, como ocurre en otras, procesos dinámicos de conocimiento y de aprendizaje. Así hay que verlas, con sus pros y sus contras. No son eventos cerrados y herméticos, $\mathrm{y}$, en ese sentido, inamovibles. Intentemos estar mentalmente preparados para ello. No concibamos ni los espacios ni los tiempos periodísticos como compartimentos estancos, parados y cerrados. No lo son. Hemos de crecer entre todos, en sociedad. Ese dinamismo nos dará entusiasmo y panorámica sobre lo que glosamos y acerca de cómo lo realizamos.

\section{Kinesia y proxémica}

Todo en comunicación nos ofrece una lectura, o varias. Tengamos en cuenta que es así. Por lo tanto, utilicemos bien los códigos y los lenguajes, en función, por supuesto, de los medios, de los diversos espacios, de los formatos y de los soportes. Los lenguajes orales y gestuales y toda la ciencia de la kinesia y de la proxémica han de ser instrumentos de comunicación bien utilizados, y para ello debemos conocer y exprimir bien sus posibilidades. Ganaremos con esa visión, y expresamente cuando nos referimos a cuestiones relacionadas con accidentes y sucesos.

\section{Coraje}

El consejo final es que vayamos siempre hacia delante con valentía y sin precipitaciones. Merece la pena hacer cada día una buena labor, en la medida que podamos, con voluntad, con las mejores intenciones. La recompensa en la tarea de servicio público a la ciudadanía será, sin duda, extraordinaria. Pensemos que el derecho a la información es un derecho personal que se transfiere, tácitamente, a los periodistas, quienes, en esta interpretación, han de realizar un uso decoroso, lo más decoroso posible. El coraje no debe faltar.

\section{UN PERIODISMO BASADO EN LA ÉTICA}

Marean los números, pero están ahí. La existencia humana está rodeada de un gran número de circunstancias que a menudo hay que objetivar para entender lo que ocurre, e incluso para comprender lo que no sucede. Un niño, un infante de menos de 14 años, contempla al año unas 9.000 horas de imágenes con un contenido claro y pernicioso de violencia, de "alta violencia" podríamos decir. Algunos informativos emblemáticos de la 
televisión contienen hasta un tercio de noticias basadas o relacionadas con datos o hechos definidos por la violencia, por los llamados sucesos. Es únicamente, este dato, una muestra del modelo televisivo vigente, al que se suman el resto de medios de comunicación de no tanto impacto anímico y cuantitativo.

Por otro lado, no solo cabe hablar de la violencia: hay que referirse, asimismo, a contenidos poco adecuados para las audiencias que, potencial y realmente, consumen algunas informaciones, como decimos, poco recomendables. Me refiero concretamente a las imágenes relacionadas con el sexo o con actuaciones poco éticas, que también aparecen en las franjas de mayor consumo en busca de la rentabilidad de unos contenidos que, a menudo, poco tienen que ver con esa función de servicio público que todas las empresas periodísticas deberían tener (por ley, la tenían hasta ahora). Lo malo es que este argumento se esgrime, pero no se respeta.

Encender la televisión es ver suicidios, controversias, gentes vociferando, imágenes agresivas, guerras, pandemias, modelos económicos en puro conflicto, desarrollos desorbitados, consumos estruendosos, motivaciones desequilibradas, opulencias en contraste con marginalidades, etc. Hay todo un compendio de informaciones que, sin su debido contexto, llegan a hacer daño, y, desde luego, pocas veces se entienden.

Las prisas, las búsquedas de mayores audiencias y el deseo de llegar los primeros, siempre los primeros, con los impactos visuales y/o noticiosos más fuertes producen distorsiones. Repetimos el aserto de MacLuhan con el que empezábamos, en el sentido de que el medio es el mensaje. Creemos que ahora es así más que nunca, por desgracia, más que cuando se enunció esta aseveración.

Como quiera que la precipitación y la competencia atroz nos conducen a una realidad profesional y empresarial, en el mundo periodístico, que necesita un análisis y puede que alguna revisión, nos planteamos la necesidad de unos constantes encuentros mediáticos sobre Comunicación y Ética que vislumbren los derechos de la sociedad. La idea es abundar en todo esto, en más cuestiones controvertidas y comprometidas, y, sobre todo, llegar a algún tipo de conclusiones que nos sirvan a todos. Juntos, compañeros y compañeras, siempre podemos, y, además, debemos. No dejemos que nos convenzan de lo contrario.

\section{BIBLIOGRAFÍA A TENER EN CUENTA}

- BARROSO GARCÍA, Jaime. El proceso de la información de actualidad en televisión. Editado por el Instituto Oficial de Radio Televisión Española. Madrid, 1992. 
- BLUM, R. A., y LINDHEIM, R. D. Programación de las cadenas de televisión en horario de máxima audiencia. Editado por el Instituto Oficial de Radio-Televisión Española. Madrid, 1989.

- BUENO, GUSTAVO. Telebasura y democracia. Punto de Lectura. Barcelona, 2003.

- CASTILlA DEL PINO, Carlos. Teoría de los sentimientos. Editoral Tusquets. Barcelona, 2001.

- CEBRIÁN HERREROS, Manuel. Información televisiva: mediaciones, contenidos, expresión y programación. Ed. Síntesis. Madrid, 1998.

- CORTÉS, José Ángel. La estrategia de la seducción: la programación en la Neotelevisión. Editorial Eunsa. Navarra, 2001.

- ECO, Umberto. Apocalípticos e integrados. Editorial Lumen. Barcelona, 1999.

- ESPARZA, José Javier. Informe sobre la televisión: el invento del maligno. Editado por Criterio Libros. Madrid, 2001.

- GARCÍA NOBLEJAS, Juan José. Medios de conspiración social. Editorial Eunsa. Pamplona, 1997.

- GRIJELMO, Álex. La seducción de las palabras. Edit. Taurus Ediciones. Madrid, 2000.

- HABERMAS, Jürgen. Historia y crítica de la Opinión Pública: la transformación estructural de la vida pública. Ediciones Gustavo Gili. Barcelona, 1994.

- MARSALL, McLuhan. Comprender los medios de comunicación: las extensiones del ser humano. Editorial Paidós Comunicación. Barcelona, 1996.

- MATELSKI, Marilyn J. Programación diurna de televisión. Editado por el Instituto Oficial de Radio y Televisión. Madrid, 1992.

- PRIEST, Stephen. Teorías y filosofías de la mente. Editorial Cátedra. Madrid, 1994.

- RODRÍGUEZ FERRÁNDIZ, Raúl. Apocalypse show: intelectuales, televisión y fin de milenio. Editado por Biblioteca Nueva. Madrid, 2001.

- SARTORI, Giovanni. Homo Videns: la sociedad teledirigida. Ed. Taurus. Madrid, 2002. 
- SARTRE, Jean Paul. El existencialismo es un humanismo. Editorial Edhasa. Barcelona, 1999.

- VAN DIJK, T. A. Texto y contexto. Editorial Cátedra. Madrid, 1970.

- WOLF, Mauro. Los efectos sociales de los media. Editorial Paidós. Barcelona, 1994.

\section{INFORMES UTILIZADOS}

- Estudio, análisis e interpretación de la formación de los periodistas (el caso de Murcia).

- Tesis doctoral publicada por su autor, Juan Tomás Frutos, en Editum: http://www.tdr.cesca.es/TESIS_UM/AVAILABLE/TDR-0929109120746//TomasFrutos.pdf

- Informe Anual de la Profesión Periodística, editado por la Asociación de la Prensa de Madrid, años 2007, 2008 y 2009. Director: Pedro Farias Batlle.

\section{MÁS FUENTES BIBLIOGRÁFICAS}

- BAUDRILLARD, Jean. La transparencia del mal. Ensayo sobre los fenómenos extremos. Editorial Anagrama. Barcelona, 1991.

- BUENO, Gustavo. Televisión: apariencia y verdad. Ediciones Gedisa. Barcelona, 2000.

- HARTELEY, John. Los usos de la televisión. Editorial Paidós. Barcelona, 2000.

- IMBERT, GÉRAD. Los escenarios de la violencia. Conductas armónicas y orden social en la España actual. Editado por Icaria. Barcelona, 1992.

- LACALlE, Charo. El espectador televisivo. Ediciones Gedisa. Barcelona, 2001. 